\title{
Answering yes-no questions about causes: Question acts and question categories
}

\author{
MURRAY SINGER \\ University of Manitoba, Wimnipeg, Manitoba, Canada
}

\begin{abstract}
Three experiments examined the cognitive process of answering yes-no questions about causes. Singer's VAIL model of question answering predicted that readers would take longer to correctly answer "no" than "don't know" to such questions. In Experiment 1, the antecedent sentences used either the causal conjunction so or because. Experiment 2 compared so with an implicit causal link. In all conditions, the main prediction was strongly supported. However, when the questions referred to brief stories in Experiment 3, correct "no" and "don't know" response latencies did not differ. It was concluded that (1) VAIL identifies the cognitive operations underlying the answering of causal questions; (2) answering yes-no questions about causes resembles answering yes-no questions about case-filling elements; (3) the yes-no versus wh-distinction is orthogonal to the type of relation asked about; and (4) studying question answering about sentences will contribute to the understanding of question answering about text.
\end{abstract}

In a series of studies, Singer (1981, 1984, in press) proposed and evaluated a process model of the mental operations underlying the answering of yes-no and wh- questions about sentences and brief texts. The model, called VAIL, identified processing stages of encoding the question, determining whether the antecedent message included any information pertinent to the question, retrieval of the requested information from short-term memory and long-term memory, comparison, response index bookkeeping, and response. The model has addressed (1) the verification of the assertions and the implications of a message; (2) the subject's use of a variety of realistic responses, such as "yes," "no," "don't know," and "implied"; and (3) the similarities and differences between sentence verification, yes-no questions, and whquestions.

The goal of the present study was to apply VAIL to yesno questions about causes, such as "Was the kingdom wealthy because oil was discovered?' There were several reasons for undertaking this task. First, Singer (1984) inspected yes-no questions about the concepts filling the agent, patient, and instrument semantic cases (Fillmore, 1968). For example, "Was the stone kicked by a plumber?" asks about the agent of "kicking the stone." This question can be propositionally represented as (KICK, AGENT:PLUMBER?, PATIENT:STONE) (Kintsch, 1974; Singer, 1984, p. 286), and it interrogates a single argument of the proposition, namely, PLUMBER. In con-

This research was supported by Grant No. A9800 from the Natural Sciences and Engineering Research Council of Canada. I am grateful to Arthur Graesser for his helpful comments about the manuscript. and would like to thank Lorna Jakobson and Hope McEwan, who conducted the experimental sessions. Requests for reprints should be sent to the author at the Department of Psychology, University of Manitoba, Winnipeg, Man., Canada R3T 2N2 trast, "Was the kingdom wealthy because oil was discovered?" asks about the truth of the entire proposition, "oil was discovered," and its relation to the "wealth of the kingdom." Accordingly, it is plausible that mental operations of answering the latter question might be different from those previously discussed by Singer (1984).

A second reason to undertake this task concerns the importance of the relation of cause in the representation of discourse meaning. Numerous investigators have argued that the coherence of text depends on the existence of causal connections among text elements (Black \& Bern, 1981; Graesser, Robertson, Lovelace, \& Swinehart, 1980; Lehnert, 1978; Trabasso, Secco, \& van den Broek, 1984). Schank and Abelson (1977), for example, proposed that the gist of a narrative, to a great extent, can be captured in terms of a causal chain of events. The centrality of cause in text meaning makes it particularly important to understand how one answers questions about this relation.

A third reason for undertaking the present study was to propose an improvement in the taxonomic analysis of question types, especially with regard to yes-no questions. To explain this proposal, it is necessary to review the current treatment of yes-no questions. Lehnert (1977, p. 53), for example, correctly pointed out that a comprehensive treatment of question processing requires that questions be classified according to the concepts about which they ask, and not according to the interrogative words used. She argued that "How long did it take?" is not a how question in the sense of "How did Sue get here?" Accordingly, Lehnert (1978) presented a list of 13 conceptual question categories. To cite one example, a quantification question asks about a quantity or amount, for example. "How many people are here?"

Lehnert (1978) assigned yes-no questions to a conceptual category called verification questions, which "ask 
about the truth of an event" (Lehnert, 1978, p. 63). However, this definition is too restrictive, because a yesno question can also ask about the truth of the relation between two events, such as "Did John leave because the party broke up?" Although her definition did not refer to the accuracy of relations, Lehnert pointed out that a verification question can ask about a link in a causal chain (Lehnert, 1978, p. 64). However, in her examination of the memory search processes of answering yesno questions, Lehnert (1978, pp. 150-151) emphasized examples that tended to interrogate only the elements of a simple event. In "Did John order lasagna?" for example, the focus might be upon the accuracy of "lasagna." This implies that yes-no questions are ones that ask about the accuracy of specific arguments of a proposition, rather than of whole propositions or relations.

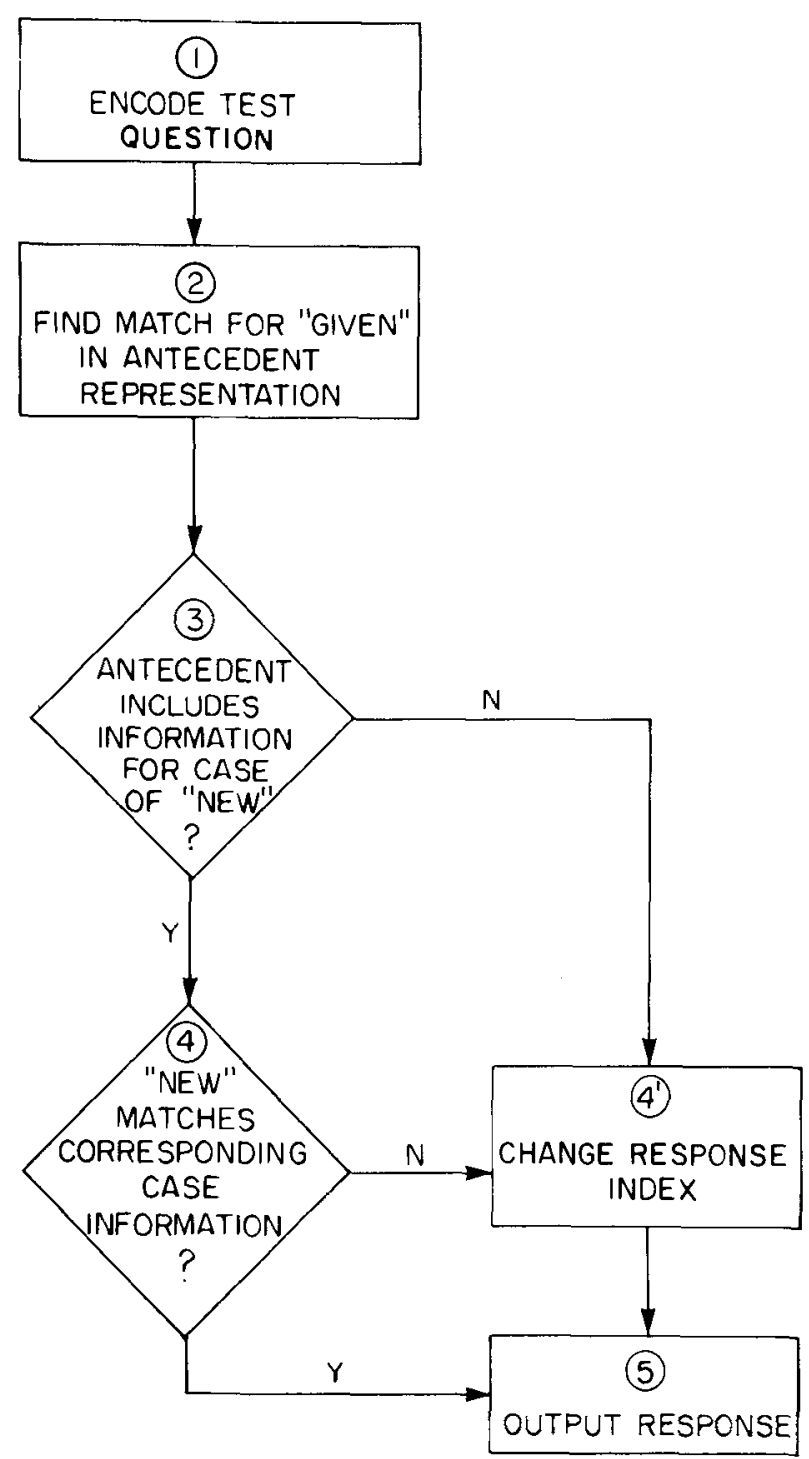

Figure 1. Flow diagram of model VAIL5 for answering yes-no questions. (From "Toward a model of question answering: Yes-no questions" by M. Singer, 1984, Journal of Experimental Psychology: Learning, Memory \& Cognition, 10, pp. 285-297.)
The same tendency appears in other treatments of yesno questions. For example, Clark and Clark (1977) primarily discussed simple examples of yes-no questions, such as "Was it John that hit Bill?" Graesser and Murachver (1985) also listed yes-no questions as one type of question.

An examination of Lehnert's (1978) question categories reveals that it is possible to ask yes-no questions about every type of concept that she discussed. For example, "Did the igloo melt because the sun came out?" asks about the cause of the igloo melting, and "Were there 150 jelly beans in the jar?" asks about a quantity of jelly beans. Accordingly, it is proposed that whether a question asks for the report of certain information or, alternatively, the verification of certain information, is orthogonal to the type of concept, event, or link that is being asked about.

If the yes-no versus wh- distinction is independent of the type of interrogated concept, then it should be possible to show that there are certain invariants in the answering of yes-no questions. Therefore, the VAIL model of answering yes-no questions (Singer, 1984) should generate accurate predictions for questions about causes.

\section{The Model}

VAIL is an additive-stage process model that invokes the principles specified by Sternberg (1969). In particular, the time needed to answer a question is assumed to reflect the execution of a series of cognitive operations whose durations are additive.

Singer $(1981,1984)$ inspected VAIL with reference to materials illustrated by Sentence Set 1 . The subjects viewed either Sentence 1a, 1b, or Ic, followed by Question Id. The answer to ld is "yes," after la and "no" after $1 \mathrm{~b}$. We can also judge that it is reasonable to answer "don't know" when ld follows Ic.
1a. The hunter shot the deer with the gun.
b. The hunter shot the bear with the gun.
c. The hunter shot with the gun.
d. Did the hunter shoot a deer?

The version of VAIL that is relevant to this task, VAIL5 (Singer, 1984), is shown in Figure 1. The stages and assumptions of VAIL5 have been described in detail in several locations (Singer, 1981, 1984, 1985), and will be reviewed only briefly here. VAIL5 addresses the encoding of the question and the operations that follow this encoding. Consider the example question, "Did the hunter shoot a deer?" At the outset, it is assumed that an internal "response index" is initialized with the value "yes" (Clark \& Chase, 1972). At Stage 1 (Figure 1), the question is encoded to its propositional form, (SHOOT, HUNTER, DEER) (Kintsch, 1974), This representation distinguishes between the "given" element, hunter, and the "new" or interrogated element, deer (Haviland \& Clark, 1974). At Stage 2, the given element is matched with the corresponding part of the representation of the antecedent 
sentence. At Stage 3, an attempt is made to retrieve information in the semantic case of the new question element from the antecedent representation. If this is successful, then the retrieved information is compared with the interrogated concept at Stage 4. If the two match (e.g. deer-deer), the reader can register the response "yes" at Stage 5. However, if Stage 4 reveals a mismatch (c.g., deer-bear), then the response index must be changed to "no"' at Stage 4' before a response can be made.

For don't know questions, a failure to retrieve the requested information occurs at Stage 3. Control flows directly to Stage $4^{\prime}$. The response index is changed to "don't know" and the response is registered at Stage 5.

This analysis specifies operation sequences 1-2-3-4-5, 1-2-3-4-4'-5, and 1-2-3-4'-5 for yes, no, and don't know questions, respectively. Singer's (1984) key prediction, therefore, was that it would take longer to respond "no" than "don't know" in this task. "No" was also predicted to take longer than "yes," but yes questions have the confounding advantage of an extra content word in common with their antecedents (e.g., the critical element deer), as compared with the no questions. The mean response time for "no" answers significantly exceeded "don't know" answers (Singer, 1981. Experiment 1; Singer, 1984, Experiments $1 \& 2$ ), providing support for the main prediction.

Sentence Set 2 is completely analogous to Set 1, but the yes-no question $(2 \mathrm{~d})$ asks about the cause of the paint spilling. Question $2 \mathrm{~d}$ should be answered "yes," "no," and "don't know" when it follows Sentences $2 a, 2 b$, and $2 c$, respectively.
2a. The platform collapsed so the paint spilled.
b. Anne bumped the paint so the paint spilled.
c. The paint spilled so Anne got the mop.
d. Did the paint spill because a platform collapsed?

It is possible to directly apply VAIL5 to Set 2 . At Stage 1, the question, "Did the paint spill because a platform collapsed?" is propositionally represented as follows: P1 (SPILL, PAINT), P2 (COLLAPSE. PLATFORM), P3 (CAUSE, P2?, P1). At Stage 2, the question's given information, which is that the paint spilled, is matched with the corresponding part of the antecedent sentence. This match succeeds for all three antecedents, $2 \mathrm{a}, 2 \mathrm{~b}$, and $2 \mathrm{c}$.

For the yes and $n o$ antecedents, $2 \mathrm{a}$ and $2 \mathrm{~b}$, the cause of the paint spilling is retrieved at Stage 3. Control flows to Stage 4, at which the new proposition of the question is compared with the corresponding component of the antecedent. For Sequence $2 a-2 d$, this results in the match the platform collapsed - the platform collapsed, and the response "yes" may be output at Stage 5. For sequence $2 \mathrm{~b}-2 \mathrm{~d}$, in contrast, Stage 4 reveals a mismatch, the platform collapsed-Anne bumped the paint, resulting in a "no" response.

The matching process at Stage 4 must be more complex for materials such as Set 2 than for Set 1. For the present example, whole propositions rather than single arguments are compared at Stage 4 . However, this does not alter the basic architecture of the model.

For Sequence $2 \mathrm{c}-2 \mathrm{~d}$, Stage 3 fails to retrieve a cause of the paint spilling. The response index is changed to "don 't know" at Stage 4", and the response is registered. The yes, no, and don't know operation sequences are the same as for the corresponding yes-no questions about semantic cases. Once again, the main prediction is that correct "no" response latencies will exceed correct "don't know" response latencies.

\section{EXPERIMENT 1}

\section{Method}

Verbal materials. In Sentence Set 2, it was seen that the correct answer to Question $2 \mathrm{~d}$ could vary as a function of its antecedent. The intention in Experiment 1 was to cycle questions such as $2 \mathrm{~d}$ across the response conditions yes, no, and don't know. However, materials such as Set 2 were not completely satisfactory. The reason for this is that the given proposition appeared in the last clause of the yes and no antecedents, $2 \mathrm{a}$ and $2 \mathrm{~b}$, but in the first clause of Sentence $2 c$. If all the materials were similar to Set 2 , the subjects would have the opportunity to learn that when the given part of the question referred to the first clause of the antecedent, the correct answer was "don't know."

To avoid this problem, the materials consisted of 30 sets similar to Set 3 below. In Sentences $3 a$ to $3 c$, their causes and consequences were linked by the conjunction so, as in Set 2 . In contrast, the conjunction because was used in Sentences $3 \mathrm{~d}$ to $3 \mathrm{f}$. Beyond this difference, Sentences $3 \mathrm{~d}$ through $3 \mathrm{f}$ were analogous to $3 \mathrm{a}$ through $3 \mathrm{c}$, in that they required the answers "yes," "no," and "don't know," respectively. when followed by Question $3 \mathrm{~g}$.
3a. Fred parked on the glass so Fred had a flat.
b. A vandal cut Fred's tire so Fred had a flat.
c. Fred had a flat so Fred called the garage.
d. Fred had a flat because Fred parked on some glass
e. Fred had a flat because a vandal cut Fred's tire.
$f$. Fred called the garage because Fred had a flat.
g. Did Fred have a flat because he parked on some glass?

One disadvantage of this arrangement was that response condition, conjunction, and position of the interrogated clause still were not completely independent of one another. That is, so questions asked about the first clause of the antecedents in the don't know condition and the second clause in the yes and no conditions and vice versa for the because questions. However, it was considered unlikely that the subjects could notice and take advantage of this complex relation.

Halliday and Hasan (1976) pointed out that causal questions may ask about either the cause of a physical event or the reason for a person's action. The present yes-no questions interrogated both physical causes, as in Set 3, and reasons, as in "Did Steve leave the picnic because his allergies acted up?"

Six counterbalanced lists were constructed from the 30 sentence sets. Across the lists. each set appeared once in each of the six response (yes, no. don't know) $\times$ conjunction (so, because) conditions. The following procedures were used to construct List 1: (1) the 30 sentence sets were randomly assigned to six groups of five sentences apiece; (2) each group was then randomly assigned to one of the six experimental conditions; ( 3 ) the individual sentences were assigned to random list positions, subject to two restrictions. First, at least two of the sentences in each group had 10 appear in each half of the list. Second, no two consecutive sentences in the list could be from the same group. For the remaining 
five lists, the assignments of groups to experimental conditions were varied following a Latin square design.

In the resulting lists, sentences using each conjunction preceded each of the three responses equally often, and the test questions presupposed each the first and the last clause of their antecedents $50 \%$ of the time. Finally, each list began with six practice items, one for each condition.

Subjects. The subjects were 60 students of introductory psychology at the University of Manitoba; they participated for course credit. The data of 1 subject, who committed errors on more than 10 of the 30 experimental trials, were excluded from analysis.

Procedure. The sessions were conducted with groups of 1-4 individuals. Each group was randomly assigned to view one of the six lists. The subjects read the materials on video monitors located in two booths in each of two rooms. The materials were displayed at a distance of $44 \mathrm{~cm}$ from the subjects. All experimental events were controlled by an Apple II + computer.

At the beginning of each trial, a fixation point appeared on the screen for $1 \mathrm{sec}$. When it disappeared, the antecedent sentence was displayed for $4 \mathrm{sec}$, occupying two rows on the monitor. The subjects then had $5 \mathrm{sec}$ to answer the question. After the question disappeared, a 5-sec intertrial interval preceded the beginning of the next trial.

The subjects registered their responses using three labeled buttons on a response panel. Because the crucial prediction concerned the "no" and "don't know" responses, each subject group was randomly assigned to use the index finger of the right hand to answer "no" and the middle finger of the right hand to answer "don't know," or vice versa. All subjects used the index fingers of their left hands to respond "yes." The computer automatically recorded the responses and response times to millisecond accuracy. The subjects were not informed that the first six sequences constituted practice.

\section{Results}

The data of main concern were the correct response latencies, shown in Table 1 . Analysis of variance was applied to these scores, alternately treating subjects $\left(F_{1}\right)$ and sentences $\left(F_{2}\right)$ as the random variable. Both response and conjunction were "within-" variables for both analyses. An $\alpha$ value of .05 will be used, unless otherwise specified.

The response effect was highly significant $\left[F_{1}(2,126)\right.$ $=100.4, M S \mathrm{e}=122,625 ; F_{2}(2,58)=39.6, M S \mathrm{e}=$ 137,181]. This reflected means of $2,362,2,963$, and $2,689 \mathrm{msec}$ for "yes," "no," and "don't know" responses, respectively. No other effects approached significance, except two interactions involving the list variable in the subjects-random analysis. Table 1 shows that very similar latencies were observed for the so and because conjunctions. The mean correct "no" and "don't know" latencies were compared by $t$ tests, which reveal

Table 1

Mean Correct Response Latencies (in Milliseconds) and Error Rates in Experiment 1

\begin{tabular}{lccc}
\hline \multirow{2}{*}{$\begin{array}{c}\text { Conjunction } \\
\text { of Antecedent }\end{array}$} & Yes & No & Don't Know \\
\cline { 2 - 4 } So & $2336(.043)$ & $2978(.183)$ & $2711(.113)$ \\
Because & $2387(.026)$ & $2947(.188)$ & $2666(.096)$ \\
Mean & $2362(.035)$ & $2963(.186)$ & $2689(.105)$ \\
\hline
\end{tabular}

Note-Error rates are in parentheses. that "don't know" latencies were significantly faster $\left[t_{1}(114)=3.97 ; t_{2}(56)=2.87\right]$.

Table 1 also shows the error rates for each of the six conditions. Across the six experimental conditions, the correlation between response latencies and error rates was .983. This is a very familiar outcome in studies of sentence verification and yes-no question answering (Carpenter \& Just, 1975; Clark \& Chase, 1972; Singer, 1984). One explanation of this correlation is as follows: Conditions with more underlying operations have longer latencies, because their durations are additive, and higher error rates, because each stage has a certain probability of yielding incorrect output (Carpenter \& Just, 1975). As a result, the chances of avoiding an error become smaller as the number of operations increases.

An alternative explanation of the positive correlation between latencies and errors is that there are a greater number of ambiguous or confusing test questions in some response conditions than others. Consider, for example, the sequence "Anne bumped the paint so the paint spilled; Did the paint spill because a platform collapsed?" Although this was constructed as a no sequence, a reader might believe it possible that the collapse of a platform participated causally in the spilling of the paint. An ambiguous question would probably require more time to answer and lead subjects to respond incorrectly more frequently.

To address this possibility, an examination was made of those sentence sets with approximately equal numbers of errors in the no and don't know conditions (see Singer, 1984 , p. 291). In the so condition, 19 sentence sets met this criterion. These sets had error rates of $10.8 \%$ and $11.7 \%$ and mean latencies of $2,926 \mathrm{msec}$ and $2,715 \mathrm{msec}$ for the no and don't know conditions, respectively. In the because condition, 15 sets met the criterion. They had error rates of $10.1 \%$ and $10.1 \%$ and latencies of $2,867 \mathrm{msec}$ and $2,658 \mathrm{msec}$ for the no and don't know conditions, respectively. These results make it unlikely that the "no" versus "don't know" latency difference can be attributed to unequal ambiguity associated with the two conditions.

\section{Discussion}

The results supported the main prediction of VAIL5: the subjects needed more time to correctly respond "no" than "don't know." This confirms the suggestion that there are certain facets of answering yes-no questions that are independent of the type of concept or relation that is being asked about. According to VAIL5, the "no" latencies exceeded the "don't know" latencies because the "no" response requires the execution of the additional comparison stage, Stage 4.

The error patterns also replicated the findings concerning yes-no questions about case-filling elements. For example, Singer (1984, Experiment 1) detected a correlation between response latencies and error rates of .936, which is similar to the present value of .983. Singer (1984) also examined sentence sets with approximately equal no 
and don't know error rates, and reported that the "no" latencies exceeded the "don't know" latencies by over $200 \mathrm{msec}$ for these sets.

It should be noted that whether subjects view sentencequestion sequences as ambiguous is influenced by the instructions they receive. Singer's (1984) subjects were instructed to interpret, "The aunt purchased the pen; Did the aunt purchase some flowers?" as a contradiction. The subjects usually replied "no" to the question. In contrast, Glucksberg and McCloskey”s (1981) subjects answered "don't know" to a similar sequence. They were instructed to follow the rationale that the aunt might have purchased some flowers, too. However, there was little evidence of confusion on the subjects' part in either study.

The main goal of Experiment 2 was to replicate Experiment 1 . However, to increase the generality of the finding, the because condition was replaced with a condition in which the antecedent message included no causal conjunction, as in "the platform collapsed, the paint spilled."

Although the no-conjunction condition was considered worthy of inspection, it was not anticipated that the absence of the conjunction would have any effect on the pattern of response latencies across the response conditions. The reason for this is that readers strive to identify a connection or "bridge" between superficially unrelated sentences (Haviland \& Clark, 1974). These bridges are frequently causal in nature. Empirical studies have suggested that comprehension is not greatly hampered by the absence of causal connectives. For example, Haberlandt and Kennard (1981) reported that reading rates for sentences and words do not significantly increase in the absence of a pertinent causal connective, and that the reading rate for phrases increases only slightly. Black and Bern (1981) found that readers integrate causally linked ideas in the absence of an explicit connective.

Therefore, it was predicted that the "no" response latencies would exceed "don't know" latencies, both in the presence and in the absence of the conjunction. Neither a conjunction main effect nor a response $\times$ conjunction interaction was anticipated.

\section{EXPERIMENT 2}

\section{Method}

Experiment 2 was identical to Experiment 1 except that because antecedents, as in Sentences $3 \mathrm{~d}$ to $3 \mathrm{f}$ of Experiment 1, were replaced with sequences such as $4 \mathrm{~d}$ to $4 \mathrm{f}$, which included no causal conjunction.
4a. Fred parked on some glass so Fred had a flat
b. A vandal cut Fred's tire so Fred had a flat
c. Fred had a flat so Fred called the garage.
d. Fred parked on some glass. Fred had a flat.
e. A vandal cut Fred's tire. Fred had a flat.
f. Fred had a flat. Fred called the garage.
g. Did Fred have a flat because he parked on some glass?

The new sentences were constructed simply by deleting the word "because" from the because antecedents of Experiment 1, and then inverting the clauses. For example, 3d, "Fred had a flat because
Fred parked on some glass," became 4d, "Fred parked on some glass. Fred had a flat." There were no other changes in the materials of Experiment 2.

The subjects were 78 individuals from the same pool as that used in Experiment 1. The data of 4 subjects who made errors on more than 10 of the experimental trials were discarded. Finally, the procedure was identical to that of Experiment 1.

\section{Results}

The mean correct response latencies are shown in $\mathrm{Ta}$ ble 2 . The response effect was significant $\left[F_{1}(2,136)=\right.$ 100.6, $M S \mathrm{e}=139,012 ; F_{2}(2,58)=48.0, M S \mathrm{e}=$ $126,347]$. Correct "no" latencies exceeded correct "don't know" latencies by $223 \mathrm{msec}\left[t_{1}(144)=3.85 ; t_{2}(56)=\right.$ 2.43]. No other latency effects reached significance.

Analysis of variance was also applied to the error rates, treating subjects as the random variable. The response effect was significant $[F(2,136)=11.0, M S \mathrm{e}=1.001]$ reflecting means of $.116, .206$, and .120 for "yes," "no," and "don't know" responses, respectively. Error rates were also higher with no conjunction than with so $[F(1,68)=7.09, M S e=.823]$. Finally, there was a significant response $\times$ conjunction interaction $[F(2,136)$ $=4.17, M S \mathrm{e}=.553]$. The interaction reflected the fact that the yes error rate was considerably larger in the absence of a conjunction, whereas no and don't know rates did not show this pattern. Finally, the list main effect was not significant, and there were no other interactions.

\section{Discussion}

The response latencies closely paralleled those measured in Experiment 1: In both conjunction conditions, the "no" latencies exceeded the "don't know" latencies. The overall magnitude of this difference, 223 msec, was comparable to the value of $274 \mathrm{msec}$ measured in Experiment 1. This outcome lends additional support to the VAIL model.

As anticipated, the no-conjunction latencies did not significantly exceed those measured for "so." However, there was a difference between the error rates of these conditions. This difference may be linked to the response $x$ conjunction interaction in the error rates, which reflected a considerable increase in no-conjunction errors for "yes" responses only. This suggests that the absence of the conjunction did hinder the encoding of the causal link in a small proportion of cases. However, this effect was apparently not additive with the slight degree of extra confusion that appears to exist when subjects judge the no and don't know sequences.

In Experiment 3, brief stories replaced single sentences

Table 2

Mean Correct Response Latencies (in Milliseconds) and Error Rates in Experiment 2

\begin{tabular}{lccc}
\hline & \multicolumn{3}{c}{ Response } \\
\cline { 2 - 4 } Conjunction & Yes & No & Don't Know \\
\hline So & $2486(.060)$ & $3144(.182)$ & $2906(.124)$ \\
No Conjunction & $2561(.152)$ & $3157(.232)$ & $2949(.116)$ \\
Mean & $2523(.116)$ & $3150(.206)$ & $2927(.120)$ \\
\hline
\end{tabular}

Note-Error rates in parentheses. 
as the antecedent messages. This change was made primarily to permit an inspection of the processes of answering causal yes-no questions about text. However, it was considered possible that the course of processing and, hence, the latency pattern of Experiment 3 might differ from that of Experiments 1 and 2. One reason for this is that there is more opportunity for subjects to forget some of the ideas conveyed by a text than by a single sentence. Suppose that a subject forgot the cause asked about by questions in the yes and no conditions. This might result in an error on the subject's part. Alternatively, the subject might initiate a search of long-term memory in an attempt to retrieve the relevant cause.

A metacognitive corollary of heightened forgetting particularly concerns the don't know response condition. Consider a don't know sequence from Experiment 1: "The kingdom was wealthy so a monument was built; Was the kingdom wealthy because oil was discovered?' Upon encountering the question in this sequence, a reader can feel relatively confident that the antecedent did not mention why the kingdom was wealthy. In contrast, if the same antecedent sentence were embedded in a story, it might be difficult for the reader to decide whether the cause had not been mentioned in the story or whether it had been forgotten. The reader might then try to reinstate the requested cause from long-term memory (Kintsch \& van Dijk, 1978). This, in turn, would inflate the "don't know" latencies.

\section{EXPERIMENT 3}

\section{Method}

Verbal materials. The verbal materials were six stories of seven sentences, and accompanying sets of three questions. Table 3 shows one of the stories and accompanying questions. Whenever possible, the materials of Experiment 1 were incorporated into the stories. Each story consisted of three experimental sentences, to which the questions referred, plus four filler sentences. The filler sentences always appeared in Positions 1, 3, 5, and 7.

There were three versions of each story. Across these versions, each experimental sentence appeared in three different forms. For example, in one story, the subject encountered one of the following: "The king was poisoned so the king died," "The king had a heart attack so the king died," or "The king died so the citizens mourned." Regardless of the alternative that was shown, the pertinent question was, "Did the king die because he was poisoned?' In this way, each sequence of experimental sentence and corresponding question appeared once in each of the response conditions yes, no, and don't know.

Three test lists were constructed. For List 1 , the 18 experimental sentences in the six stories were randomly assigned to response condition, subject to the constraint that there be six sentences in each condition. Furthermore, the stories could have two but not three sentences in the same response condition. For the remaining two lists, the experimental sentences were cycled across response conditions following a Latin square scheme.

The three questions that appeared after each story were shown in a single random order. This order was independent of the order of the corresponding experimental sentences in the story. The stories themselves appeared in a random order that remained constant for the three lists. Each list began with one practice story, accompanied by three questions, one in each response condition.
Unlike Experiments 1 and 2, all experimental antecedent sentences contained the conjunction so. There were two reasons for this. First, the conjunction variable did not affect the latency patterns across response conditions in Experiments 1 and 2. Second, the complexity of the stories was expected to prevent the subjects from noticing that only don't know questions interrogated the first rather than the second clause of their antecedent sentences.

Subjects and Procedure. The subjects were 52 men and women from the same pool that was used in the other experiments. The procedure was identical to that of Experiment 1, except for the chronology of the trials. On each trial, a fixation point appeared for $1 \mathrm{sec}$. Then, the seven sentences comprising the story appeared in sequence, for $4 \mathrm{sec}$ each. After a 5 -sec delay, the three questions were presented. The subjects had up to $5 \mathrm{sec}$ to respond to each question, and the questions were separated by an interval of $5 \mathrm{sec}$. The intertrial interval was $10 \mathrm{sec}$.

\section{Results}

The data of 8 subjects who answered incorrectly on 7 or more of the 18 experimental trials were excluded from further analysis. It is likely that the high error rates of these subjects were due to the increased difficulty of the questions when presented in the context of brief stories. It is noted that the response latency pattern for all 52 subjects was virtually identical to that observed for the 44 low-error individuals.

Analysis of variance was applied to the mean correct latencies of the remaining 44 subjects. Subjects and sentences within stories were alternately treated as the random variable. The only significant effect was that of response $\left[F_{1}(2,82)=23.2, M S \mathrm{e}=121,025 ; F_{2}(2,24)=\right.$ $15.7, M S \mathrm{e}=71,896]$. This reflected mean latencies of $2,821,3,265$, and 3,244 msec for the "yes," "no," and "don't know" responses, respectively. The "no" and "don't know" latencies did not differ significantly $\left[t_{1}(84)\right.$ $=1.19 ; t_{2}(32)=0.23$ ]. Error rates of $6.1 \%, 24.7 \%$, and $18.4 \%$ were measured for the yes, no, and don't know conditions, respectively.

\section{Discussion}

Experiment 3 was designed to examine the cognitive processes of answering causal yes-no questions with reference to brief stories. Although Experiment 3 might appear to be a simple extension of Experiments 1 and 2, it was argued that the response latency pattern of Experiment 3 might differ from those of Experiments 1 and 2 . This turned out to be the case. In contrast with the previous experiments, "don't know" latencies were not faster than "no" latencies, but instead were similar in magnitude to them. As explained earlier, this may be attributable to the fact that, in the context of even a brief story, readers may use strategies of memory search that differ from those that are invoked when one answers questions about single sentences. When a question probes for information that was absent from a single sentence, the reader is likely to feel confident that additional search of memory will be fruitless. This would result in a rapid "don't know" response. When the same question follows a story, there is much more reason for the reader to con- 
Table 3

\begin{tabular}{|c|c|c|}
\hline $\begin{array}{l}\text { Sentence or } \\
\text { Question Number }\end{array}$ & Role of Sentence & Passage and Questions* \\
\hline Sl & Filler & King Edmond of Walonia was loved by all. \\
\hline S2 & Experimental & $\begin{array}{l}\text { Oil was discovered so the kingdom was } \\
\text { wealthy./ The harvests were excellent } \\
\text { so the kingdom was wealthy./ The king- } \\
\text { dom was wealthy so a monument was } \\
\text { built. }\end{array}$ \\
\hline S3 & Filler & Then the troubles began. \\
\hline S4 & Experimental & $\begin{array}{l}\text { The king was poisoned so the king died./ } \\
\text { The king had a heart attack so the king } \\
\text { died./ The king died so the citizens } \\
\text { mourned. }\end{array}$ \\
\hline S5 & Filler & Then wicked Prince James became king. \\
\hline S6 & Experimental & $\begin{array}{l}\text { But an earthquake struck so the dragon's } \\
\text { den opened./ But the wizard cast a spell } \\
\text { so the dragon's den opened./ But the } \\
\text { dragon's den opened so the sheep fled. }\end{array}$ \\
\hline S7 & Filler & $\begin{array}{l}\text { The dragon attacked the kingdom and } \\
\text { killed James. }\end{array}$ \\
\hline Q1 & & Did the king die because he was poisoned? \\
\hline Q2 & & $\begin{array}{l}\text { Was the kingdom wealthy because oil was } \\
\text { discovered? }\end{array}$ \\
\hline Q3 & & $\begin{array}{l}\text { Did the dragon's den open because an } \\
\text { earthquake struck? }\end{array}$ \\
\hline
\end{tabular}

sider the possibility that the requested information has been forgotten. One might therefore try to reinstate the requested information from one's long-term memory of the message, resulting in relatively longer "don't know" responses.

The approximate equality of the "no" and "don't know" latencies is viewed as being coincidental. The reason for this is that the proposed search of long-term memory in the don't know condition is assumed to be of variable duration. Singer (1985) has proposed that task parameters, such as text complexity, and the limit on answer time influence the time that subjects will search longterm memory before answering "don't know."

\section{GENERAL DISCUSSION}

The results of Experiments 1 and 2 were consistent with VAIL's predictions concerning the relative latencies of answering yes-no questions about causes. This outcome constitutes important support for the VAIL model, which was previously tested in the context of simpler yes-no questions, ones concerning the agents, patients, and instruments of an action. Accordingly, VAIL is viewed as identifying principles and mechanisms of question answering that extend to a broad range of question types.

Considered in another way. Experiments 1 and 2 indicate that there are certain features of answering yes-no questions that do not change as a function of the type of concept or relation about which the question asks. This has important implications for the classification of question types. In particular. it is proposed that "yes-no" or "verification" should not be treated as a single category in a one-dimensional taxonomy of question types. Instead, both yes-no and wh- questions can interrogate any type of concept or relation. This suggests a two-dimensional taxonomy of questions, with the yes-no versus whdichotomy constituting one dimension, and "category" (Lehnert, 1978) forming the other.

What is the nature of this yes-no versus wh- dichotomy? According to Clark and Clark (1977, p. 88), both yes-no and wh- questions belong to the speech act category called directive, in that they both ask the listener or reader to provide certain information. However, yes-no questions, such as "Did the aunt purchase some flowers?" more specifically ask the reader to verify a concept, fact, or relation; whereas wh- questions, such as "What did the aunt purchase?" request that the reader report the corresponding information. I wish to propose the following: (1) The speech acts of yes-no and wh- questions are request verification and request report, respectively; (2) for the purpose of classifying question types, it is convenient to refer to the yes-no versus wh- dichotomy as one of "question act"; (3) an improved taxonomy of questions shows question act and question category (Lehnert, 1978) functioning as two orthogonal dimensions. This scheme is outlined in Table 4, which shows request-report and request-verification questions for four of Lehnert's (1978) question categories.

Besides question act, there is another difference between yes-no and wh- questions. Yes-no questions convey the expectation that the interrogated element is, in fact, accurate. Consider, for example, the question, "Did John 
Table 4

Two-Dimensional Analysis of Question Types

\begin{tabular}{|c|c|c|c|c|}
\hline \multirow[b]{2}{*}{ Question Act } & \multicolumn{4}{|c|}{ Question Category } \\
\hline & $\begin{array}{c}\text { Causal } \\
\text { Antecedent }\end{array}$ & $\begin{array}{c}\text { Goal } \\
\text { Orientation }\end{array}$ & $\begin{array}{c}\text { Concept } \\
\text { Completion }\end{array}$ & Quantification \\
\hline $\begin{array}{c}\text { Request report } \\
\text { (wh-) }\end{array}$ & $\begin{array}{l}\text { How did the } \\
\text { glass break? }\end{array}$ & $\begin{array}{l}\text { Why did Anne } \\
\text { rob the bank? }\end{array}$ & $\begin{array}{l}\text { What did John } \\
\text { eat? }\end{array}$ & $\begin{array}{l}\text { How many people } \\
\text { are here? }\end{array}$ \\
\hline $\begin{array}{l}\text { Request verification } \\
\text { (yes-no) }\end{array}$ & $\begin{array}{l}\text { Did the glass } \\
\text { break because } \\
\text { it fell off } \\
\text { the table? }\end{array}$ & $\begin{array}{l}\text { Did Anne rob } \\
\text { the bank } \\
\text { because she } \\
\text { needed money } \\
\text { for her father's } \\
\text { operation? }\end{array}$ & $\begin{array}{l}\text { Did John eat } \\
\text { some stew? }\end{array}$ & $\begin{array}{c}\text { Are there eight } \\
\text { people here? }\end{array}$ \\
\hline
\end{tabular}

eat a hot dog?"' This question asks about the accuracy of hot dog. One would never ask this question unless one had the expectation that what John ate was a hot dog. If one did not have any information about what John might have eaten, one would instead ask, "What did John eat?"

This expectational assumption of yes-no questions is reminiscent of Wason's (1965) argument that negative sentences likewise embody such expectations. According to Wason, the statement, "John didn't eat a hot dog," would normally be uttered only when the speaker assumed that the listener had some reason to believe that John did eat a hot dog. It may be suggested that these two observations are not independent of one another. One of the contexts in which one would utter, " $(\mathrm{No})$, John didn't eat a hot dog" is in response to the yes-no question, "Did John eat a hot dog?"' The expectations underlying yes-no questions are likely to have an impact on the answerer's response.

Consider next the results of Experiment 3. When compared with the results of Experiments 1 and 2, the results of Experiment 3 indicate that certain features of answering yes-no questions change as a function of the complexity of the antecedent message. In particular, it is easier to decide that requested information has not appeared in a single sentence than in a complex story. In this regard, Experiment 3 might be viewed as providing a boundary limitation on the usefulness of the VAIL5 version of VAIL: that is, for texts even as brief as seven sentences, it appears that there is some tendency of readers to search long-term memory before agreeing that they do not know something. In contrast, when Singer's (1982) subjects answered yes-no questions about case-filling elements in the context of three-sentence passages, the "no" latencies did significantly exceed "don't know" latencies. The difference between the interrogated concepts of Singer (1982) and of Experiment 3 makes it impossible to directly compare the two results. However, it appears that for messages just seven sentences in length, subjects examine long-term memory before responding "don't know."

A corollary of this point is that it may be necessary to study question answering about single sentences in order to achieve an understanding of the cognitive processes of answering questions about text. The reason for this is that the elementary operations that contribute to answering questions about text may be obscured by the complexity of the task and of the representation of the message. In particular, although the present results suggest the involvement of operations such as comparison (Stage 4) and principles such as response index bookkeeping, it seems unlikely that an exclusive focus upon lengthier text messages would have permitted the identification of these factors. In spite of this, the conceptual similarity of answering questions about sentences and about texts suggests that there must be extensive overlap between the cognitive processes of the two activities.

It is important to address the relation between the VAIL model and other current analyses of question answering. In particular, both Lehnert $(1977,1978)$ and Graesser (Graesser \& Murachver, 1985; Graesser et al., 1980) have presented detailed treatments of question answering from the perspectives of artificial intelligence and cognitive psychology, respectively. These accounts have shown considerable convergence. Both Lehnert and Graesser have emphasized the need for a well-defined conceptual representation of text meaning, and have proposed that each identifiable question category has an associated memory-search procedure. Furthermore, both investigators have focused on complex question categories, such as questions about causes, reasons, motives, and consequences.

What, then, is the relation between these approaches and the VAIL model? Lehnert and Graesser's most important analyses are ones that specify the details corresponding to VAIL's short-term memory and long-term memory retrieval stages. VAIL, in contrast, asserts that memory retrieval needs to occur, but does not identify the mechanisms of that retrieval. Rather, VAIL addresses the arrangement of the constituent mental operations in a variety of subtly different question-answering tasks. As such, the investigations of Lehnert and Graesser, on the one hand, and VAIL, on the other, form complementary projects that address different facets of question answering.

Finally, Lehnert $(1977,1978)$ considered several features of yes-no questions that merit consideration. First, she pointed out (Lehnert, 1977, p. 56) that a yes-no question can interrogate any of its meaning elements. For example, "Did John give Mary the book?"' can ask about 
the accuracy of John, Mary, book, or even give (cf. "No, John sold Mary the book"). In normal discourse, which element is being asked about can be identified by many factors, such as choice of syntax, the contrastive use of definite and indefinite articles, and vocal stress (e.g., "Did John give Mary the book?') (Hornby, 1974). However, it is also possible for a yes-no question to interrogate an entire fact. If a student is asked, "Did Hamlet hand the cup to Laertes?" it might be necessary to evaluate the veridicality of each concept in the sentence. Furthermore, it would be relatively straightforward to construct a version of VAIL that addressed such a task. In this vein, Carpenter and Just's (1975) constituent comparison model evaluated the accuracy of each propositional constituent underlying their test sentences.

Second, Lehnert (1977) has pointed out that, in ordinary conversation, yes-no questions are not typically answered with a simple "yes" or "no," but also with an elaboration. For example, in response to the question. "Did John give Mary the book?" it is more polite to answer, "No, John gave it to Anne," than simply "no." As a corollary of this point, Lehnert (1977) proposed that a negative answer to a yes-no question results in the reader's generation of a "secondary" question. For example, if the answerer determines that John didn't give the book to Mary, he or she might undertake to answer the secondary question. "To whom did John give the book?"

The present distinction between question acts and question categories offers a suggestion for the generation of secondary questions: "In the event of a negative answer to a yes-no question, generate a secondary question by changing the question act from request-verification to request-report, and keep the question category the same." Following this scheme, the question, "Was it John who gave Mary the book?" yields the secondary question, "Who gave Mary the book?" In some circumstances, however, the meaning of the discourse will influence the choice of the secondary question. For example, depend ing on the gist of the message, the correct secondary question to "Did John eat a hot dog?" might not be "What did John eat?" but rather "Why didn't John eat a hot dog?" (Lehnert, 1977, p. 67). This and other facets of yes-no questions will require further study.

\section{REFERENCES}

BLACK, J. B., \& BERN, H. (1981). Causal inference and memory for events in narratives. Journal of Verbal Learning \& Verbal Behavior. 20, $267-275$
Carpenter, P. A., \& JUST. M. A. (1975). Sentence comprehension: A psycholinguistic model of verification. Psychological Review, 82, 45-73.

Clark, H. H., \& Chase, W. G. (1972). On the process of comparing sentences against pictures. Cognitive Psychology, 3, 472-517.

Clark, H. H.. \& Clark, E. V. (1977). Psychology and language. New York: Harcourt Brace Jovanovich.

Fillmore, C. J. (1968). The case for case. In E. Bach \& R. Harms (Eds.), Universals in linguistic theory. New York: Holt, Rinehart \& Winston.

Glucksberg, S., \& MCCloskey, M. (1981). Decisions about ignorance: Knowing that you don't know. Journal of Experimental Psychology: Human Learning \& Memory, 7, 311-325.

Graesser, A. C., \& Murachver, T. (1985). Memory search procedures in question answering. In A. Graesser \& J. Black (Eds.), The psychology of questions. Hillsdale, NJ: Erlbaum.

Graesser, A. C., Robertson, S. P., Lovelace, E. R., \& Swinehart, D. M. (1980). Answers to why-questions expose the organization of story plot and predict recall of actions. Journal of Verbal Learning \& Verbal Behavior, 19, 110-119.

Haberlandt, K. F., \& Kennard, M. (1981, November). Causal and adversative connectives facilitate text comprehension. Presented at the annual meeting of the Psychonomic Society, Philadelphia.

Halliday, M. A. K., \& Hasan, R. (1976). Cohesion in English. London: Longman.

Haviland, S. E., \& Clark, H. H. (1974). What's new? Acquiring new information as a process in comprehension. Journal of Verbal Learning \& Verbal Behavior, 13, 512-521.

HoRnBy. P. A. (1974). Surface structure and presupposition. Journal of Verbal Learning \& Verbal Behavior, 13, 530-538.

KINTSCH, W. (1974). The representation of meaning in memory. Hillsdale. NJ: Eribaum.

Kintsch, W., \& VAN DiJK, T. A. (1978). Toward a model of text com prehension and production. Psychological Review, 85, 363-394.

LEHNERT, W. (1977). Human computational question answering. Cognitive Science, 1, 47-73

LEHNERT, W. G. (1978). The process of question answering. Hillsdale, NJ: Erlbaum.

SChank, R., \& Abelson, R. (1977). Scripts, plans, goals, and understanding. Hillsdale, NJ: Erlbaum.

SiNGER, M. (1981). Verifying the assertions and implicatons of language. Journal of Verbal Learning \& Verbal Behavior, 20, 46-60.

Singer. M. (1982). Answering questions from text: A process model. In A. Flammer \& W. Kintsch (Eds.), Discourse processing. Amsterdam: North-Holland.

Singer, M. (1984). Toward a model of question answering: Yes-no questions. Journal of Experimental Psychology: Learning, Memory \& Cognition. 10, 285-297.

Singer, M. (in press). Answering wh- questions about sentences and text. Journal of Memory \& Language.

Sternberg, S. (1969). The discovery of processing stages: Extensions of Donders ' method. In W. Koster (Ed.), Attention and performance Il. Acta Psychologica, 30, 276-315.

Trabasso. T., Secco, T., \& van den Broek, P. (1984). Causal cohesion and story coherence. In H. Mandl, N. Stein, \& T. Trabasso (Eds.), Learning and comprehension of text. Hillsdale, $\mathrm{NJ}$ : Erlbaum.

WASON, P. C. (1965). The contexts of plausible denial. Joumal of Verbal Learning \& Verbal Behavior, 4, 7-11.

(Manuscript received May 16, 1985; revision accepted for publication July 6, 1985.) 